\title{
Immunoglobulin G4-Related Inflammatory Pseudotumor Presenting as a Solitary Mass in the Stomach
}

\author{
Hong Ryeol Cheong, Bong Eun Lee, Geun Am Song, Gwang Ha Kim, Sung Gyu An and Won Lim \\ Department of Internal Medicine, Pusan National University School of Medicine, Busan, Korea
}

Immunoglobulin G4 (IgG4)-related disease (IgG4RD) is a relatively recently recognized entity that is histopathologically characterized by an extensive infiltration of lymphocytes and IgG4-positive plasma cells with dense fibrosis. IgG4RD is now known to affect any organ system, and a few cases of gastrointestinal lesions have also been reported. However, solitary IgG4RD of the stomach is still very rare. Furthermore, as it can mimic malignant conditions, it is important to recognize this disease to avoid unnecessary surgery. Herein, we present a case of IgG4RD presenting as an isolated subepithelial mass in the stomach. Clin Endosc 2016;49:197-201

Key Words: Immunoglobulin G4-related sclerosing disease; Pseudotumor; Stomach

\section{INTRODUCTION}

Immunoglobulin G4 (IgG4)-related disease (IgG4RD) is a relatively recently defined condition that is histologically characterized by an extensive infiltration of lymphocytes and IgG4-positive plasma cells with storiform fibrosis. ${ }^{1}$ At present, it is known that various organs can be affected by IgG4RD, including the pancreas, bile duct, gallbladder, liver, lung, salivary gland, retroperitoneum, and gastrointestinal tract. ${ }^{2}$ However, isolated IgG4RD of the stomach is still very rare. Here, we report a case of IgG4RD of the stomach presenting as a subepithelial mass without any other organ involvement.

\section{CASE REPORT}

A 27-year-old woman presented for the evaluation of high

Received: May 4, 2015 Revised: June 26, 2015

Accepted: July 11, 2015

Correspondence: Bong Eun Lee

Department of Internal Medicine, Pusan National University School of Medicine and Biomedical Research Institute, Pusan National University Hospital, 179 Gudeok-ro, Seo-gu, Busan 49241, Korea

Tel: +82-51-240-7225, Fax: +82-51-254-3127, E-mail: bongsul@hanmail.net

(c) This is an Open Access article distributed under the terms of the Creative Commons Attribution Non-Commercial License (http://creativecommons.org/ licenses/by-nc/3.0) which permits unrestricted non-commercial use, distribution, and reproduction in any medium, provided the original work is properly cited. blood pressure. Autosomal dominant polycystic kidney disease was diagnosed on abdominal computed tomography (CT), and she was referred to our gastroenterology clinic for further evaluation of an intramural enhancing mass in the gastric fundus that was incidentally found on the CT scan (Fig. 1). She had no gastrointestinal complaints, and physical examination showed no abnormalities. The laboratory results were unremarkable except for hypocytic and hypochromic anemia (hemoglobin, $10.1 \mathrm{~g} / \mathrm{dL}$ ). She underwent an esophagogastroduodenoscopy. Helicobacter pylori-positive lymphofollicular gastritis was seen, and, macroscopically, a 4-cm subepithelial mass with surface ulceration was found on the fundus (Fig. 2A, B). Endoscopic ultrasonography (EUS) showed a $3.4 \times 1.6 \mathrm{~cm}$ well-circumscribed homogeneous hypoechoic mass located mainly in the muscularis mucosa and submucosa (Fig. 2C). Because multiple biopsy specimens only showed chronic ulcer on microscopic examination, laparoscopic wedge resection was performed to rule out tumors with malignant potential such as a neuroendocrine tumor (NET) or gastrointestinal stromal tumor (GIST). Grossly, the resected specimen showed a well-defined whitish-gray solid subepithelial mass (Fig. 3). On microscopic examination, dense fibrosis admixed with inflammatory cells was seen composing the submucosal mass that extended to the subserosa (Fig. 4A). Bland-looking spindle cells were arranged in a storiform pattern in the collagenous 

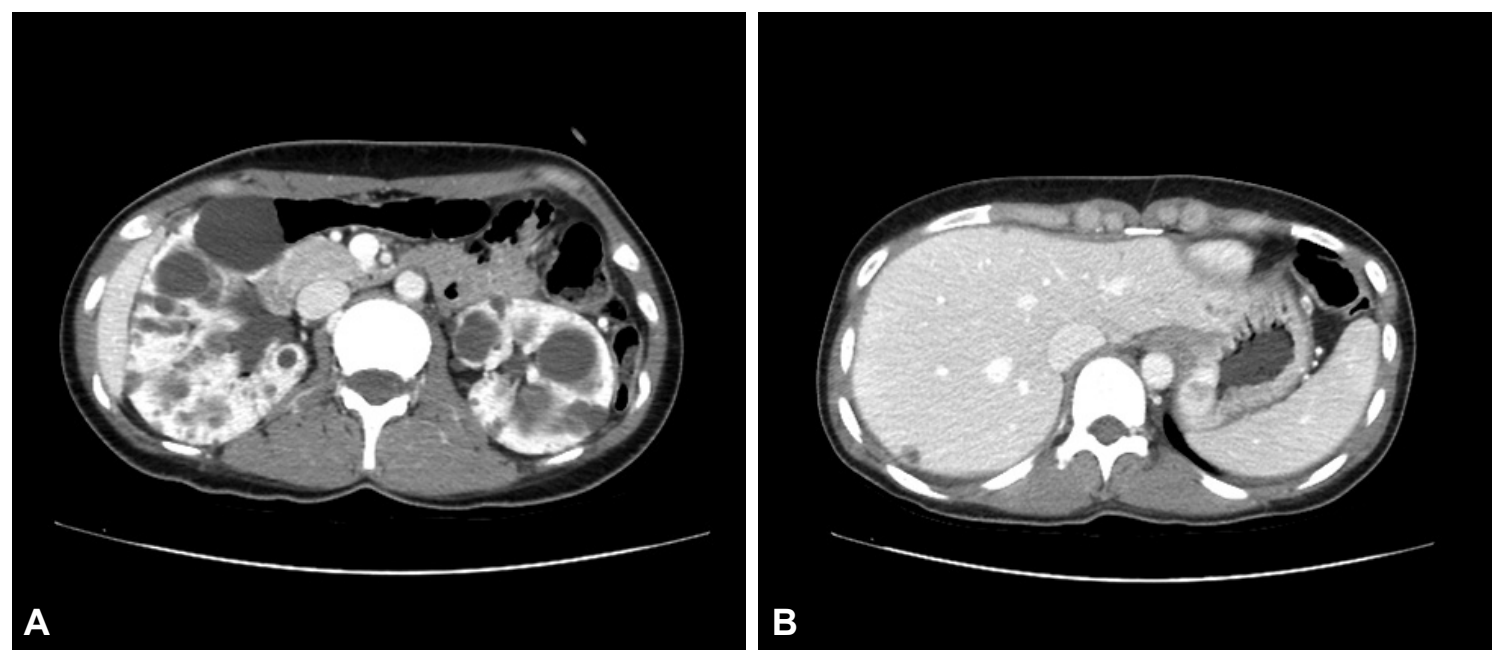

Fig. 1. Abdominal computed tomography images showing multiple cysts in both kidneys (A) and an intramural enhancing mass in the gastric fundus (B).
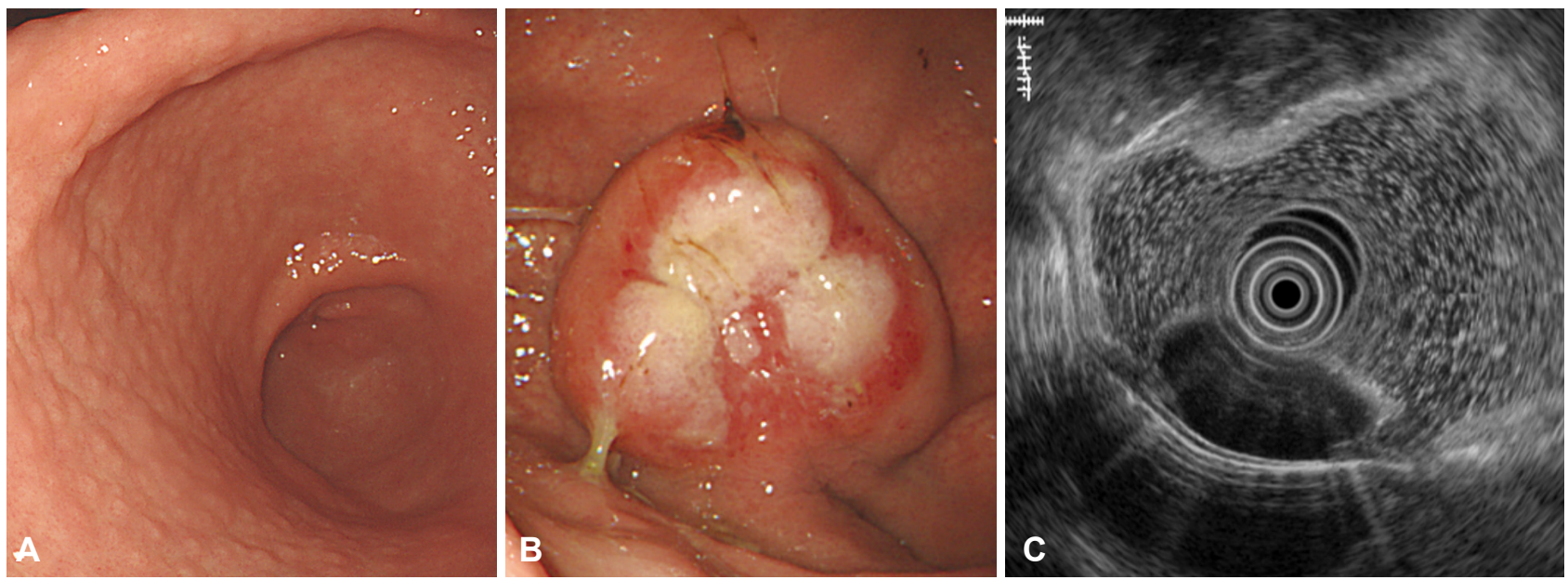

Fig. 2. Endoscopic findings. (A) Helicobacter pylori-positive lymphofollicular gastritis. (B) An approximately 4-cm, hard, fixed subepithelial mass with distinct ulceration on the surface, located in the fundus. (C) Endoscopic ultrasonography image showing a $3.4 \times 1.6 \mathrm{~cm}$ homogeneous hypoechoic mass located in the muscularis mucosa up to the submucosa.

stroma (Fig. 4B), and there was a dense infiltration of polymorphous inflammatory cells composed predominantly of plasma cells with a few lymphocytes, eosinophils, and neutrophils (Fig. 4C). These spindle cells showed one to two mitoses per 10 high power fields (HPFs), and positive staining for smooth muscle actin and negative staining for ALK, desmin, CD34, DOG-1, c-kit, and S-100. Additional immunohistochemical staining revealed increased IgG-positive and IgG4-positive plasma cells (402/HPF and 102/ $\mathrm{HPF}$, respectively), and the ratio of IgG4+/IgG+ plasma cells was $25.3 \%$ (Fig. 4D, E). Because these pathological features were compatible with IgG4RD, and there was no evidence of any other organ involvement, isolated gastric IgG4RD was finally diagnosed. The serum IgG and IgG4 levels were not elevated (1,012 and $295 \mathrm{mg} / \mathrm{L}$, respectively). She was discharged without significant postoperative complications, and there has been no evidence of disease recurrence during the 1-year follow-up period.

\section{DISCUSSION}

IgG4RD was first proposed as a new clinicopathological entity by Kamisawa et al. ${ }^{3}$ in 2003 as a multisystemic disease in patients with autoimmune pancreatitis. IgG4RD is histologically defined as an intensive infiltration of IgG4-positive plasma cells and T-lymphocytes with storiform fibrosis, and clinically known to respond well to steroids. ${ }^{1}$ Multiple organs can be affected synchronously or metachronously, including the pancreas, biliary tree, liver, kidneys, salivary gland, orbit, breast, pericardium, aorta, skin, lungs, prostate, meninges, retroperitoneum, and gastrointestinal tract. ${ }^{2}$ Recently, many cases 

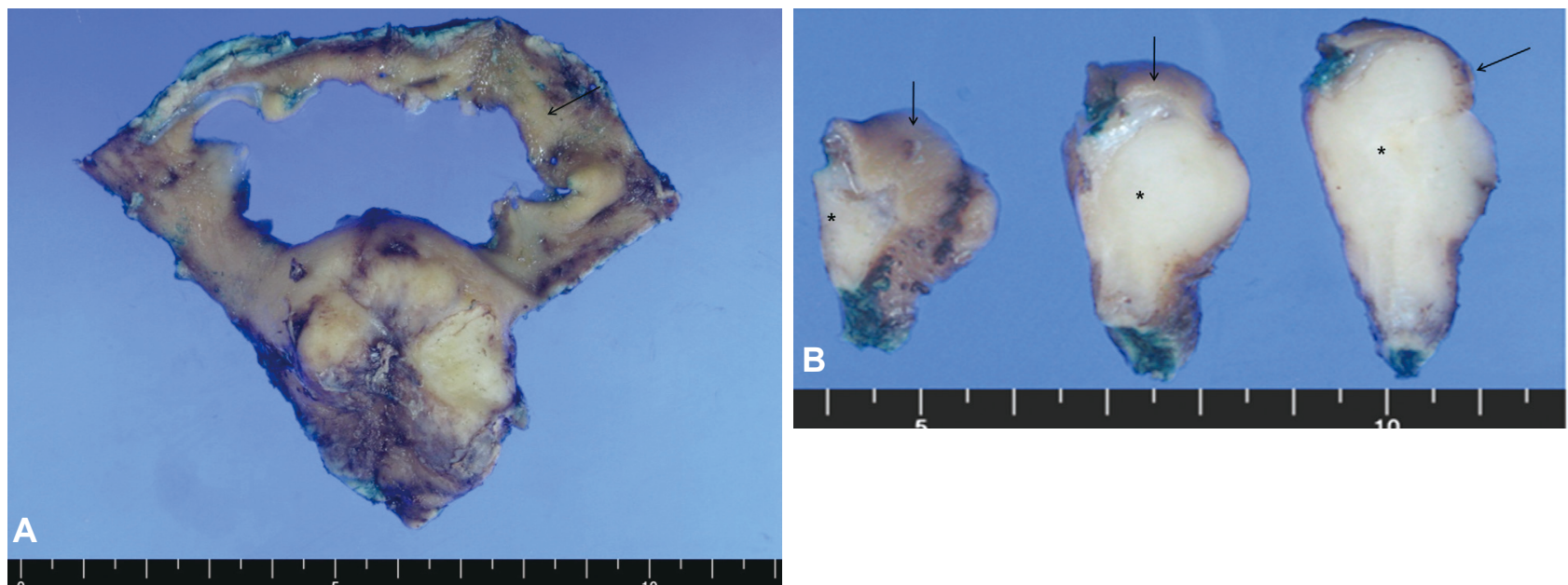

Fig. 3. Gross findings after formalin fixation. (A, B) On the specimen section, a well-defined homogeneous gray-white solid submucosal mass (asterisks) is identifiable. The gastric mucosa (arrows) is unremarkable.
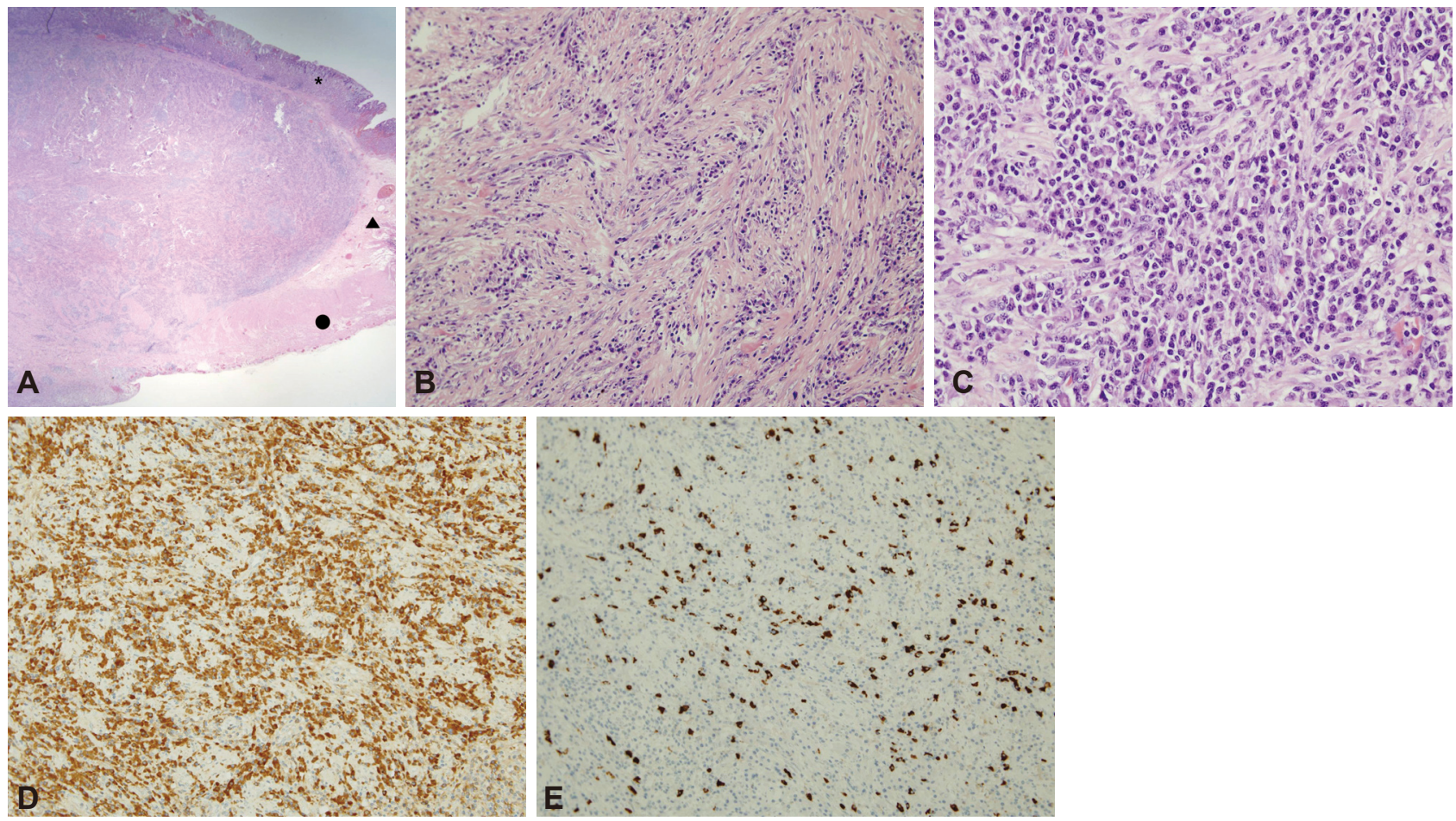

Fig. 4. Pathologic findings. (A) Dense fibrosis admixed with inflammatory cells composing the submucosal mass that extends to the subserosa (asterisk, mucosa; arrowhead, submucosa; circle, muscularis propria; H\&E stain, $\times 12.5)$. (B) Bland-looking spindle cells arranged in a storiform pattern (H\&E, $\times 200)$. (C) Fibroblastic cells admixed with dense lymphoplasmacytic cells $(\mathrm{H} \& \mathrm{E}, \times 400)$. (D) Immunoglobulin $\mathrm{G}(\mathrm{lgG})$ immunohistochemical staining showing increased numbers of $\mathrm{lgG}$-positive plasma cells in the stroma (402/high power field [HPF], $\times 200)$. (E) IgG4 immunohistochemical staining revealing increased numbers of IgG4-positive plasma cell infiltration (102/HPF, $\times 200)$; the ratio of lgG4+/lgG+ plasma cells was $25.3 \%$.

of IgG4RD affecting organs other than the pancreas have been reported, such as IgG4-related inflammatory pseudotumors of the liver, ${ }^{4}$ lungs, ${ }^{5}$ and greater omentum ${ }^{6}$ with or without autoimmune pancreatitis, and isolated IgG4RD seems to have been increasingly detected owing to an increased awareness of this disease entity.

However, IgG4RD in the stomach is still rare. On the basis of the eight cases reported thus far, the gastric manifestations of this disease seem to consist of two types: polypoid mass-like (six cases) or ulcerative (two cases) lesions (Table 1). Rollins et al. ${ }^{7}$ first described 5 to $6 \mathrm{~cm}$ gastric IgG4-related pseudotumors with no evidence of any other organ involvement as confirmed with laparoscopic resection. Chetty et al. ${ }^{8}$ reported two patients with gastric sclerosing nodular IgG4RD that was 
Table 1. Clinicopathological Features of Gastric Immunoglobulin G4-Related Disease

\begin{tabular}{|c|c|c|c|c|c|c|c|}
\hline $\begin{array}{l}\text { Case } \\
\text { no. }\end{array}$ & Study & $\begin{array}{l}\text { Sex/Age } \\
(y r)\end{array}$ & $\begin{array}{l}\text { Endoscopic } \\
\text { finding }\end{array}$ & Location & EUS finding & $\begin{array}{l}\text { Diagnostic } \\
\text { procedure }\end{array}$ & Involved layer \\
\hline 1 & $\begin{array}{l}\text { Rollins et al. } \\
(2011)^{7}\end{array}$ & $\mathrm{~F} / 75$ & Polypoid mass, $5 \mathrm{~cm}$ & $\begin{array}{l}\text { Mid-body, great } \\
\text { curvature }\end{array}$ & NA & WR & SM \\
\hline 2 & $\begin{array}{l}\text { Chetty et al. } \\
(2011)^{8}\end{array}$ & $\mathrm{~F} / 45$ & Nodule, $1.5 \mathrm{~cm}$ & Fundus & NA & WR & SM \\
\hline 3 & $\begin{array}{l}\text { Chetty et al. } \\
(2011)^{8}\end{array}$ & $\mathrm{M} / 60$ & $\begin{array}{l}\text { Multiple nodules, up } \\
\text { to } 2.2 \mathrm{~cm}\end{array}$ & $\begin{array}{l}\text { Antrum and } \\
\text { pylorus }\end{array}$ & NA & DG & $\mathrm{MP}$ to $\mathrm{SS}$ \\
\hline 4 & Na et al. $(2012)^{9}$ & $\mathrm{M} / 56$ & Nodule, $8 \mathrm{~mm}$ & $\begin{array}{l}\text { Lower body, lesser } \\
\text { curvature }\end{array}$ & NA & ESD & SM \\
\hline 5 & $\begin{array}{l}\text { Kim et al. } \\
(2012)^{10}\end{array}$ & $\mathrm{~F} / 59$ & $\begin{array}{l}\text { Subepithelial mass, } \\
3.3 \mathrm{~cm}\end{array}$ & $\begin{array}{l}\text { Mid-body, great } \\
\text { curvature }\end{array}$ & $\begin{array}{l}\text { Homogeneous, } \\
\text { hypoechoic mass arising } \\
\text { from echo layer } 4\end{array}$ & WR & NA \\
\hline 6 & $\begin{array}{l}\text { Kim et al. } \\
(2012)^{10}\end{array}$ & $\mathrm{~F} / 54$ & Fixed mass, $2.1 \mathrm{~cm}$ & NA & $\begin{array}{l}\text { Homogeneous, } \\
\text { hypoechoic mass arising } \\
\text { from echo layer } 4\end{array}$ & WR & SS \\
\hline 7 & Present study & $\mathrm{F} / 27$ & $\begin{array}{l}\text { Subepithelial mass } \\
\text { with surface } \\
\text { ulceration, } 4 \mathrm{~cm}\end{array}$ & Fundus & $\begin{array}{l}\text { Homogeneous, } \\
\text { hypoechoic mass located } \\
\text { in the muscularis mucosa } \\
\text { up to the submucosa }\end{array}$ & WR & SM to SS \\
\hline 8 & $\begin{array}{l}\text { Fujita et al. } \\
(2010)^{11}\end{array}$ & $\mathrm{~F} / 73$ & Ulcer, $3 \mathrm{~cm}$ & $\begin{array}{l}\text { Lower body, lesser } \\
\text { curvature }\end{array}$ & NA & DG & SM to SS \\
\hline 9 & $\begin{array}{l}\text { Bateman et al. } \\
(2012)^{12}\end{array}$ & $\mathrm{M} / 77$ & Ulcer, diffuse & Body & NA & Biopsy & $\begin{array}{l}\text { Mucosa (only } \\
\text { the mucosa } \\
\text { was examined) }\end{array}$ \\
\hline
\end{tabular}

EUS, endoscopic ultrasonography; NA, not available; WR, wedge resection; SM, submucosa; DG, distal gastrectomy; MP, muscularis propria; SS, subserosal; ESD, endoscopic submucosal dissection.

diagnosed on surgical resection. Thereafter, Na et al. ${ }^{9}$ reported an 8-mm gastric nodular IgG4RD confirmed with endoscopic submucosal dissection, and Kim et al. ${ }^{10}$ described two cases of IgG4-related inflammatory pseudotumors in the stomach, in which EUS showed a well-defined homogeneous hypoechoic mass arising from echo layer 4 (muscularis propria). On the other hand, two patients presented with chronic gastric ulcerations. Fujita et al. ${ }^{11}$ reported a case with refractory gastric ulcers that worsened after standard proton pump inhibitor therapy and $H$. pylori eradication, and similarly Bateman et al. ${ }^{12}$ described a case of intractable gastric ulcer showing storiform fibrosis and abundant infiltration of IgG4-positive plasma cells. Of a total of eight cases reported, only one case of ulcerative-type IgG4RD was possible to confirm by using conventional endoscopic biopsy with elevated serum IgG4 levels. For the remaining seven cases, the patients had to undergo surgical or endoscopic resection for the final diagnosis, and their serum IgG4 levels were within the reference range. In this regard, $\mathrm{Na}$ et al. ${ }^{9}$ suggested that predominant inflammatory infiltrates of IgG4RD in the gastric submucosa while sparing the mucosa seem to make the diagnosis difficult. Furthermore, endoscopic and radiographic difficulties in dis- tinguishing IgG4RD from other malignancies or tumors with malignant potential are also reasons for a troublesome diagnosis. These situations lead to a higher possibility of unnecessary surgery in these patients, although IgG4RD is a medically treatable condition that responds well to steroid therapy.

In our case, macroscopically, a $4-\mathrm{cm}$ subepithelial mass with surface ulceration was incidentally found on the fundus, and EUS revealed a well-circumscribed homogeneous hypoechoic mass located mainly in the muscularis mucosa and submucosa. Although endoscopic biopsy failed to detect the disease, we considered laparoscopic wedge resection to rule out a NET or GIST without doubt. After obtaining the final diagnosis and reviewing similar cases in which patients had undergone unnecessary surgery, we learned that clinical awareness and suspicion of IgG4RD is the most important factor in diagnosing this disease entity. Although $H$. pylori-associated gastritis was seen in our case, there has been no evidence of a link between IgG4RD and $H$. pylori infection thus far.

In conclusion, isolated gastric IgG4RD is very rare. Because it is difficult to endoscopically differentiate IgG4RD from other potentially malignant tumors and to definitively identify the disease with conventional endoscopic biopsy, it is 
most important to recognize this disease entity to avoid unnecessary surgery. Because IgG4RD is known to respond well to steroids, it is important to attempt to confirm the disease before considering invasive surgery. Furthermore, we suggest considering IgG4RD in the differential diagnosis in the presence of a gastric subepithelial mass that has a homogeneous hypoechoic feature on EUS.

\section{Conflicts of Interest}

The authors have no financial conflicts of interest.

\section{Acknowledgments}

This work was supported by the year 2014 clinical research grant from Pusan National University Hospital.

\section{REFERENCES}

1. Umehara H, Okazaki K, Masaki Y, et al. Comprehensive diagnostic criteria for IgG4-related disease (IgG4-RD), 2011. Mod Rheumatol 2012;22:21-30.

2. Stone JH, Zen Y, Deshpande V. IgG4-related disease. N Engl J Med 2012;366:539-551.
3. Kamisawa T, Funata N, Hayashi Y, et al. A new clinicopathological entity of IgG4-related autoimmune disease. J Gastroenterol 2003;38:982-984.

4. Kanno A, Satoh K, Kimura K, et al. Autoimmune pancreatitis with hepatic inflammatory pseudotumor. Pancreas 2005;31:420-423.

5. Zen Y, Kitagawa S, Minato H, et al. IgG4-positive plasma cells in inflammatory pseudotumor (plasma cell granuloma) of the lung. Hum Pathol 2005;36:710-717.

6. Cha DH, Choi CW, Kim S, et al. An IgG4-related inflammatory pseudotumor of the greater omentum. Korean J Med 2013;84:400-404.

7. Rollins KE, Mehta SP, O’Donovan M, Safranek PM. Gastric IgG4-related autoimmune fibrosclerosing pseudotumour: a novel location. ISRN Gastroenterol 2011;2011:873087.

8. Chetty R, Serra S, Gauchotte G, Märkl B, Agaimy A. Sclerosing nodular lesions of the gastrointestinal tract containing large numbers of IgG4 plasma cells. Pathology 2011;43:31-35.

9. Na KY, Sung JY, Jang JY, et al. Gastric nodular lesion caused by IgG4-related disease. Pathol Int 2012;62:716-718.

10. Kim do H, Kim J, Park do H, et al. Immunoglobulin G4-related inflammatory pseudotumor of the stomach. Gastrointest Endosc 2012;76:451452.

11. Fujita T, Ando T, Sakakibara M, Hosoda W, Goto H. Refractory gastric ulcer with abundant IgG4-positive plasma cell infiltration: a case report. World J Gastroenterol 2010;16:2183-2186.

12. Bateman AC, Sommerlad M, Underwood TJ. Chronic gastric ulceration: a novel manifestation of IgG4-related disease? J Clin Pathol 2012;65:569570 . 